\title{
THREONINE SUPPLEMENTATION ON GUT HISTOMORPHOMETRY AND MUCIN BIOLOGY OF BROILERS
}

\author{
B. C. DEBNATH ${ }^{1 *}$, P. BISWAS ${ }^{1}$, B. ROY ${ }^{1}$ AND P. N. CHATTERJEE ${ }^{1}$ \\ ${ }^{1}$ Department of Animal Nutrition, West Bengal University of Animal and Fishery Sciences, Kolkata- \\ 700 037, West Bengal, India
}

\begin{abstract}
Threonine is one of the important limiting amino acids (after methionine and lysine) in broiler diets. Adequate threonine level is mandatory to obtain optimal growth of broilers. Threonine takes part in some important metabolic processes (uric acid formation and protein synthesis). It represents $30 \%$ of the total amino acid content of mucin. Threonine plays an immense role in gastrointestinal health and thus threonine optimization may protect the intestine from microbial infections. It is presumed that threonine level of healthy diet is not sufficient when the animal experiences a gut challenge either by microbial invasion and/or added with environmental extremes. Till date no guideline has been framed for optimizing the requirement of threonine considering the role of mucin in gut health of poultry. Hence, optimizing the supplemental threonine level in commercial broiler chicken for better performance and gut fitness is utmost necessary.
\end{abstract}

Key words: Crypt depth, Goblet cell, Mucin, Threonine, Villus height

\section{Introduction}

Threonine is essential in providing precise nutrition to poultry birds as they are not competent enough of synthesizing this amino acid de novo, thus it is nutritionally essential. L-threonine $(98.5 \%)$ is normally mixed to broiler diet to make amino acid balance in the nutrition status of the birds. Threonine helps in synthesis of uric acid, pancreatic enzyme, protein, collagen, elastin and antibody production (Sá et al., 2007). Adequate threonine level is mandatory to obtain optimal growth of birds (Kerr et al., 1999). Many researchers put forward their findings on the threonine requirements of poultry for growth performance (Rosa et al., 2001; Ahmadi and Golian, 2010), but meagre information is reported on the intestinal histomorphometry of broilers. Threonine plays an immense role to offer protection from bacterial infections in gastrointestinal tract. Hence, level of supplemental threonine requirement in the broiler diets must be optimised. The goblet cells of the intestine secrete mucins. This mucin is mainly glycoproteins in nature, principal component of which is threonine constituting around $30 \%$ of total amino acids. Mucins are synthesized and secreted by goblet cells distributed along the villi of the small intestine. Threonine is the main essential amino acid which is utilized by the goblet cells of the intestine thereby helping in the synthesis of mucins (Uni et al., 2003). The small intestine is protected by the mucin which mainly protect acidic chyme, various digestive enzymes and pathogens, filtering nutrient in the gastrointestinal tract, nutrient digestion and absorption (Horn et al., 2009; Jiang et al., 2013). 


\section{Optimisation of threonine requirement in intestinal histomorphometry}

Threonine supplementation helps in formation of tall villus that enhances the absorptive efficiency due to the increased absorptive surface area of mature epithelia (Hampson, 1986). An improved digestibility coefficient is observed due to higher villi heights which increase the activity of the digestive enzymes secreted from their tips. Increases in dietary threonine levels provide adequate threonine which has special importance as an essential amino acid, because, compared with other amino acids, it has the highest metabolism in the portal-drained viscera (Schaart et al., 2005). Villus height in broilers fed on threoninedeficient diets decreased in comparison with groups receiving adequate threonine, however, threonine supplementation (at 0.4, 0.5, 0.6, 0.7, $0.8,0.9 .1 .0,1.1 \%$ standard ileal digestible threonine with two level of protein 16 and 19\%) increased $(\mathrm{p}<0.01)$ villus height, and the crypt depth and reduced epithelial thickness and goblet cell number (Zaefarian et al., 2008). Villi height, crypt depth and villi surface increased as dietary threonine increased from $0.80 \%$ to $0.87 \%$ and decreased in $0.94 \%$ and $1.01 \%$ threonine (Heshmat et al., 2011). There was a tendency for an increase in goblet cell density as dietary threonine increased from 0.80 to $0.87 \%$ but it was not significant. Villus surface area was decreased as the threonine levels increased from $0.87 \%$ to $1.01 \%$ threonine. There was a tendency for a decrease in crypt depth when dietary threonine increased from $0.80 \%$ to $1.01 \%$. Though Saccharomyces cerevisiae supplementation did not affect broiler intestinal morphology, however, supplemental threonine improved intestinal morphology by increasing crypt depth and villi height and villi width of ileum and jejunum (Rezeipour et al., 2012). Dietary threonine supplementation, especially $110 \%$ level of Ross 308 specification, had increased villus height: crypt depth ratio significantly (Abbasi et al., 2013). Dietary
L-threonine was evaluated at $0.0 \%, 0.5 \%$, $0.75 \%$ and $1.0 \%$ level on gastrointestinal tract development in broiler chickens during summer where $0.75 \%$ L-threonine improved the intestinal morphology of broilers under hot conditions (Shirzadegan et al., 2015).

\section{Optimisation of threonine requirement in} intestinal goblet cells and mucin production Threonine concentration in the small intestine helps in synthesis of mucosal and mucin proteins, which demonstrates the importance of dietary threonine supply for gut metabolism (Nichols and Bertolo, 2008). Increasing supplementary threonine improved a significant increase in goblet cell numbers lead to production of more mucin which in turn provides protection of intestinal absorptive area. In broilers, the goblet cell density decreased when dietary treatments contained approximately 40, 70 and 100\% (based on NRC, 1994) of threonine requirement (Horn et al., 2009). However, there had a tendency for increase $(\mathrm{p}=0.09)$ in goblet cell density (cells/micrometer of villus height) as dietary threonine increased in ducklings from 0.33 to $0.82 \%$. Due to an imbalance intake of supplemental threonine, the rate of fractional protein synthesis of small intestinal mucosal protein and mucin were decreased (Wang et al., 2006).

\section{Role of threonine in preventing intestinal colonization of Salmonella and Coccidia}

Increase in threonine:lysine ratio did not affect villus width, crypt depth and villus height: villus width ratio in Salmonella infected chicken (Valizade et al., 2014a). However, villus height: villus width ratio showed a non-significant trend to increase with increase in threonine: lysine ratio. Villus height increased in adequate and excess threonine: lysine ratio diets compared with threonine deficient diet $(\mathrm{p}<0.001)$. Villus height: crypt depth ratio increased in excess threonine: lysine ratio diet compare with other treatments $(\mathrm{p}<0.05)$. Increase in threonoine: lysine ratio resulted in an increase $(\mathrm{p}<0.01)$ of 
villus height, crypt depth, villus height: villus width ratio and goblet cell density in both challenged and unchallenged group of Salmonella (Valizade et al., 2014b). In Coccidiosis of broiler birds, the intestinal morphological parameters of infected chicken in response to increase in threonine: lysine ratio did not alter (Kidd and Kerr, 1996; Wils-Plotz et al., 2013).

\section{Threonine for better gut health}

Birds fed with high dietary threonine have higher jejunal villus height, villus width and crypt depth which might be due to better utilization of threonine in the gastro intestinal tract. Threonine might have maintained the intestinal strength and vigour in addition to providing energy for normal intestinal functions (Zaefarian et al., 2008). A high protein turnover is required for basal metabolism and development of small intestine. Secondly, if we compare threonine with other amino acids, it has the highest metabolism in the portal-drained viscera (Schaart et al., 2005). The small intestine utilises around 30 to $50 \%$ of threonine along with arginine, proline, isoleucine, valine, leucine, methionine, lysine, phenylalanine, glycine and serine (Wu, 1998). Increase in supplemental threonine levels might have provided sufficient concentrations for the high turnover of mucosal tissues. Birds fed with supplemental threonine will have taller villus height which is positively related to villus surface area and the expansion of surface area that occurs with villus growth has been used to explain the increased absorptive capacity (Mitchell and Carlisle, 1995).

\section{REFERENCE}

Abbasi MA, Mahdavi AH, Samie AH and Jahanian R, 2013. Effects of different levels of dietary crude protein and threonine on performance, humoral immune responses and intestinal morphology of broiler chicks. Braz J Poult Sci, 16(1): 35-44, doi: 10.1590/S1516-635X2014000100005

Ahmadi Hand Golian A, 2010. The integration of broiler chicken threonine responses data into neural network models. Poult Sci, 89(11): 2535-2541, doi: 10.3382/ ps.2010-00884

\section{Threonine for optimum mucin production}

An attribution to increase in absorptive surface of the intestinal villi indicates relatively higher mean goblet cell number/villus of birds fed with higher supplemental threonine. Increased surface area of small intestine due to supplemental threonine is to be protected from the acidity of ingesta, digestive enzymes and harmful microbes (Horn et al., 2009). Hence, in order to protect the increased villus surface area, a good number of goblet cells might have been synthesized. A high production of mucin observed due to a significant increase in number of goblet cells and supplemental threonine also plays an important role in improvement of intestinal absorptive area (Nichols and Bertolo, 2008). On increased levels of threonine supplementation, the goblet cell numbers of small intestine have increased proportionately to the improved villus surface area, irrespective of experimental groups.

\section{Conclusion}

The beneficial effect of supplementation of threonine in terms of increased absorptive intestinal surface area along with goblet cell abundance is indicative for more production of mucin in the lumen, which may be correlated for better gut health of supplemented birds. Hence, that requirement of threonine in commercial chicken's diet needs to be reviewed critically. Supplementation of $10 \%$ more threonine over and above the recommended level may influence the overall performance of birds as well as its gut health and mucosal immunity.

Ball RO, 2001. Threonine requirement and the interaction between threonine intake and gut mucins in pigs. Degussa symposium, Banff Pork seminar. January 23, Banff, Alberta, Canada

Hampson DJ, 1986. Alteration in piglet small intestinal structure at weaning. Res Vet Sci, 40(1): 32-40, doi: 10.1016/S0034-5288(18) 30482-X

Heshmat SM, Hassan NM, Keramanshahi H, Mosavi AH and Raji A, 2011. The effect of threonine on mucin2 
gene expression, intestinal histology and performance of broiler chicken. Ital J Anim Sci, 10(2): 66-71, doi: 10.4081/ijas.2011.e14

Horn NL, Donkin SS, Applegate TJ and Adeola O, 2009. Intestinal mucin dynamics: response of broiler chicks and White Pekin ducklings to dietary threonine. Poult Sci, 88: 1906-1914, doi: 10.3382/ ps.2009-00009

Jiang Z, Applegate TJ and Lossie AC, 2013. Cloning, annotation and developmental expression of the chicken intestinal MUC2 gene. PLoS One, 8(1): e53781, doi: 10.1371/journal.pone.0053781

Kerr BJ, Kidd MT, McWard GW and Quarles CL, 1999. Interactive effects of lysine and threonine on live performance and breast yield in male broilers. J Appl Poult Sci, 8(4): 391-399, doi: 10.1093/japr/8.4.391

Kidd MT and Kerr BJ, 1997. Threonine responses in commercial broiler at 30 to 42 days. J Appl Poultr Res, 6(4): 362-367, doi: 10.1093/japr/6.4.362

Law GK, Bertolo RF, Adjiri-Awere A, Pencharz PB and Ball RO, 2007. Adequate oral threonine is critical for mucin production and gut function in neonatal piglets. Am J Physiol Gastrointest Liver Physiol, 292(5): 1293-1301, doi: 10.1152/ajpgi.00221.2006

Mitchell MA and Carlisle AJ, 1992. The effects of chronic exposure to elevated environmental temperature on intestinal morphology and nutrient absorption in the domestic fowl (Gallus domesticus). Comp Biochem Physiol A Comp Physiol, 101(1): 137-142, doi: 10.1016/0300-9629(92)90641-3

National Research Council (NRC), 1994. Nutrient Requirements of Poultry. $9^{\text {th }}$ rev. edn., National Academy Press. Washington DC

Nichols NL and Bertolo RF, 2008. Luminal threonine concentration acutely affects intestinal mucosal protein and mcuin synthesis in piglets. J Nutr, 138(7): 1298-1301, doi: 10.1093/jn/138.7.1298

Rezeipour V, Fononi H and Irani M, 2012. Effects of dietary L-threonine and Saccharomyces cerevisiae on performance, intestinal morphology and immune response of broiler chickens. S Afr J Anim Sci, 42(3): 266-273, doi: 10.4314/sajas.v42i3.8

Rosa AP, Pesti GM, Edwards Jr. HM and Bakalli RI, 2001. Threonine requirements of different broiler genotypes. Poult Sci, 80(12): 1718-1722, doi: $10.1093 / \mathrm{ps} / 80.12 .1718$

Sá, LM, Gomes PC and Cecon PR, 2007. Exigência nutricional de lisina digestível para galinhas poedeiras no período de 34 a 50 semanas de idade. R Bras Zootec, 36(6): 1846-1853, doi:10.1590/ S1516-35982007000800016

Schaart MW, Schierbeek H, Van Der Schoor SRD, Stoll B, Burrin DG et al., 2005. Threonine utilization is high in the intestine of piglets. J Nutr, 135(40): 765 770, doi: 10.1093/jn/135.4.765

Shirzadegan K, Nickkhah I and Jafari, MA, 2015. Impacts of dietary L-threonine supplementation on performance and intestinal morphology of broiler chickens during summer time. Iran J Appl Anim Sci, 5(2): 431-436

Uni Z, Smirnov A and Sklan D, 2003. Pre and post-hatch development of goblet cells in the broiler small intestine: effect of delayed access to feed. Poult Sci, 82(2): 320-327, doi: 10.1093/ps/82.2.320

Valizade MR, Sadeghi AA, Chamani M and Shawrang P, 2014a. Modulation of the intestinal health by increasing dietary threonine to lysine ratio during a Salmonella challenge in broiler chickens. Int J Biol Pharm Sci, 3(10): 2248-2258

Valizade MR, Sadeghi AA, Chamani M, Shawrang P and Feizi F, 2014b. The effect of increasing dietary threonine to lysine ratio on carcass characteristics, mucin gene expression and morphological analysis of ileum of male broiler chickens challenged with Salmonella. Int J Biosci, 5(11): 138-146, doi: 10.12692/ijb/5.11.138-146

Wang X, Qiao SY, Liu M and Ma YX, 2006. Effects of graded levels of true ileal digestible threonine on performance, serum parameters and immune function of $10-25 \mathrm{~kg}$ pigs. Anim Feed Sci Technol, 129(3): 264-278, doi: 10.1016/j.anifeedsci. 2006.01 .003

Wils-Plotz EL and Dilger RN, 2013. Combined dietary effects of supplemental threonine and purified fiber on growth performance and intestinal health of young chicks. Poult Sci, 92(3): 726-734, doi: 10.3382/ps.2012-02664

Wu G, 1998. Intestinal mucosal amino acid catabolism. The J Nutr, 128(8): 1249-1252, doi: 10.1093/jn/ 128.8.1249

Zaefarian F, Zaghari M and Shivazad M, 2008. The threonine requirements and its effects on growth performance and gut morphology of broiler chicken fed different levels of protein. Int J Poult Sci, 7(12): 1207-1215, doi: 10.3923/ijps.2008.1207.1215

Received-15.10.2020, Accepted - 25.11.2020, Published - 01.12.2020 